\title{
Comparison of Retinal Nerve Fiber Layer Thinning and Retinal Ganglion Cell Loss After Optic Nerve Transection in Adult Albino Rats
}

\author{
Giuseppe Rovere, ${ }^{1,2}$ Francisco M. Nadal-Nicolás, ${ }^{2}$ Marta Agudo-Barriuso, ${ }^{2}$ Paloma Sobrado-Calvo, ${ }^{2}$ \\ Leticia Nieto-López, ${ }^{2}$ Carlo Nucci, ${ }^{1}$ María P. Villegas-Pérez, ${ }^{2}$ and Manuel Vidal-Sanz ${ }^{2}$ \\ ${ }^{1}$ Department of Experimental Medicine and Surgery, Universitá Tor Vergata, Rome, Italy \\ ${ }^{2}$ Departamento de Oftalmología, Universidad de Murcia e Instituto Murciano de Investigación Biosanitaria-Hospital Universitario \\ Virgen de la Arrixaca (IMIB-Arrixaca), Murcia, Spain
}

Correspondence: Maria P. VillegasPérez, Edificio Departamental, Campus CC de la salud, Carretera Buenavista s/ n, 30120 El Palmar, Murcia, Spain; mpville@um.es.

Manuel Vidal-Sanz, Edificio Departamental, Campus CC de la salud, Carretera Buenavista s/n, 30120 El Palmar, Murcia, Spain; manuel.vidal@um.es.

GR and FMN-N are joint first authors.

Submitted: April 21, 2015

Accepted: May 25, 2015

Citation: Rovere G, Nadal-Nicolás FM, Agudo-Barriuso M, et al. Comparison of retinal nerve fiber layer thinning and retinal ganglion cell loss after optic nerve transection in adult albino rats. Invest Ophthalmol Vis Sci. 2015;56:4487-4498. DOI:10.1167/ iovs. 15-17145
Punpose. We compared the time-course and magnitude of retinal nerve fiber layer (RNFL) thinning with that of retinal ganglion cell (RGC) loss after intraorbital optic nerve transection (IONT) in adult rats.

Methods. At 3, 7, 12, or 21 days, or 1, 2, or 4 months after ONT, the retinas were imaged with spectral-domain optical coherence tomography (SD-OCT) using the circular-peripapillary scan and volume scan raster pattern (61 horizontal sections equally spaced) both centered in the optic nerve. In all sections, the RNFL and retinal thickness were measured to obtain the total values of the peripapillary scan and the values of three concentric sectors $(400,1200$, and $2400 \mu \mathrm{m}$ in diameter) from the volume scan. After SD-OCT, retinas were dissected and immunoreacted for Brn3a and neurofilaments ( $\mathrm{pNFH}$ ) to identify RGCs and their intraretinal axons, respectively. Total numbers of RGCs were quantified.

RESULTS. Thinning of the RNFL was first observed at 12 days in peripapillary scan (10\% decrease) and progressed up to 4 months ( $72 \%$ decrease). The volume scan showed transient RNFL swelling in central and medial sectors at 3, 7, and 12 days followed by progressive significant thinning first observed at 21 days (central sector, 30\%; medial sector, $40 \%$ ) and 12 days (peripheral sector, 15\%), respectively. Following IONT, Brn3a ${ }^{+}$RGCs decreased to approximately $80 \%, 52 \%, 17 \%, 9 \%, 5 \%, 3 \%$, and $2 \%$ at $3,7,12,21$ days, and at 1,2 , and 4 months, respectively. Retinal ganglion cell axon immunodetection decreased from 12 days onwards.

Conclusions. After IONT, RGC death is more severe and precedes thinning of the RNFL.

Keywords: retinal ganglion cells (RGCs), spectral-domain optical coherence tomography (SDOCT), Brn3a, antibodies antineurofilaments, intraorbital optic nerve transection (IONT), adult albino rats, retinal nerve fiber layer, retrograde axonal degeneration, axotomy, glaucoma, retinal neurodegeneration
G laucoma is a major cause of blindness in developed countries $^{1}$ that induces typical changes within the nerve fiber layer of the retina and optic disc, and bears as a hallmark the progressive loss of retinal ganglion cells (RGCs) with concomitants deficits of the visual field.

The axons of RGCs extend from their parent soma, situated primarily within the ganglion cell layer (GCL), ${ }^{2,3}$ to the next inner layer of the retina, the nerve fiber layer (RNFL), where they travel radially to converge with other RGC axons to form in the optic disc the head of the optic nerve (ON), which in turn conveys visual information to the brain retinorecipient nuclei. A classic model to study the effects of central nervous system injury has involved lesions of the mammalian ON. ${ }^{4-6}$ This model has allowed investigations of the functional deficits, ${ }^{7,8}$ including alterations of their axoplasmic transport properties, ${ }^{9-16}$ molecular changes,${ }^{17-22}$ activation of phagocytic microglia, ${ }^{23-25}$ and structural alterations ${ }^{26}$ that take place in the population of injured RGCs, as well as the possibility to prevent injury-induced loss with neuroprotective substances ${ }^{27-32}$ and their capacity to regenerate their axons, ${ }^{33,34}$ reinnervate their target, ${ }^{35}$ and form new synaptic contacts ${ }^{36}$ capable of mediating visual behaviors. ${ }^{37-39}$ These studies also have shown that ON injury induces progressive RGC death, ${ }^{26,40-45}$ and that the severity and time-course of RGC loss depends on a number of variables, such as the distance from the cell soma at which lesion is inflicted ${ }^{45}$ and the type of injury, crush or cut, ${ }^{26,42,46}$ that has important molecular correlates. ${ }^{17,18,47}$

Several studies have documented the progressive degeneration of the RNFL following ON injury using classical neurofibrillary staining methods ${ }^{4-6}$ or with antibodies to identify neurofilaments. ${ }^{44}$ Using quantitative and qualitative techniques to identify RGCs and RGC axons in the RNFL, we have shown that the loss of RGC axons in the RNFL only appeared evident at stages when the neurodegenerative process of the RGC population was advanced; this was observed after intraorbital optic nerve crush (IONC) or transection (IONT), ${ }^{26}$ and also after laser-induced ocular hypertension $(\mathrm{OHT})$ in adult rats ${ }^{16}$ or mice, ${ }^{15}$ thus highlighting 
the difficulties in assessing the degree of RGC survival based on the appearance of the RNFL and suggesting a time delay between RGC loss and the retrograde degeneration of the intraretinal axons. ${ }^{15,16,26,48}$

Direct observation and measurement of the thickness of the nerve fiber layer in vivo can be achieved with modern imaging techniques such as optical coherence tomography (OCT) ${ }^{49}$ or spectral-domain OCT (SD-OCT) ${ }^{50,51}$ Indeed, using SD-OCT, the thickness of the nerve fiber layer of the retina has been investigated following a variety of insults or diseases, such as acute elevation of the IOP in adult pigmented rats, ${ }^{52,53}$ IONT in adult rats ${ }^{49,51,54}$ or mice, ${ }^{50}$ IONC in adult rats ${ }^{55}$ or mice, ${ }^{56,57}$ experimentally-induced optic neuritis in adult rats, ${ }^{58}$ or experimentally-induced OHT in adult rats. ${ }^{49,52,59}$ Overall, these studies indicate that, as expected, ON injury is associated with a progressive thinning of the RNFL of the retina. Moreover, some studies have used confocal scanning laser ophthalmoscopy (CSLO) imaging techniques to investigate in vivo the decrease in RGC densities following IONT or IONC in adult pigmented mice ${ }^{50,57}$ or rats, ${ }^{51}$ in parallel with the progression of the RNFL thinning, either longitudinally ${ }^{51,57}$ or in different groups of animals. ${ }^{50}$ These reports document a correlation between RGC loss and progressive RNFL thinning, and some of these studies indicate a disagreement in the time course of these degenerative events. ${ }^{50,51,57}$ However, CSLO does not provide an accurate quantification of the total numbers of RGCs, and the time course of these studies was restricted to 4 to 5 weeks even though RGC loss has been shown to be a progressive event that lasts for several months. ${ }^{45}$ To our knowledge, the correlation between RNFL thinning in vivo and ex vivo and RGC loss in adult albino rats at short and long periods of time after IONT has not been analyzed previously.

The present studies emphasize the comparison of the in vivo and ex vivo appearance of the RNFL with the total number and topological distribution of surviving RGCs at increasing survival intervals ranging 3 days to 4 months; provide new information regarding the effects of IONT on adult albino rats; and extend our previous observations following IONT- or OHTinduced retinal injury. Specifically, we have addressed the following questions: do the time-courses of retrograde degeneration of the RNFL and the RGC population run in parallel; is there a mismatch, particularly at early time intervals after IONT, between the magnitude of RGC loss and RNFL thinning; and does RGC loss correlate with RNFL thinning, in terms of magnitude or severity? Our results demonstrated a clear mismatch between the early and rapid onset of RGC disappearance and a slower, more protracted, degeneration of the intraretinal axons with a 9-day time lapse, and this should be borne in mind when assessing RGC survival based on the RNFL appearance (short accounts of this work were presented in abstract format [Nadal-Nicolas FM, et al. IOVS 2014;54:ARVO E-Abstract 6313])

\section{Materials ANd Methods}

\section{Animal Handling and Ethics Statement}

Adult female Sprague-Dawley rats $(\approx 180$ g body weight) were obtained from the University of Murcia (Spain) breeding colony. Animal care and experimental procedures were performed in accordance with the Association for Research in Vision and Ophthalmology (ARVO) Statement for the Use of Animals in Ophthalmologic Research and the European Union guidelines for the use of animals in research, and were approved by the Ethical and Animal Studies Committee of the University of Murcia. For anesthesia, a mixture of xylazine
(10 mg/kg body weight, Rompun; Bayer, Kiel, Germany) and ketamine $(60 \mathrm{mg} / \mathrm{kg}$ body weight, Ketolar; Pfizer, Alcobendas, Madrid, Spain) were administered intraperitoneally (IP). While recovering from anesthesia, an ocular ointment (Tobrex; Alcon Cusí, S.A., Barcelona, Spain) was applied on the cornea to prevent corneal desiccation.

\section{Surgery and Animal Groups}

Intraorbital optic nerve transection of the left ON was performed at approximately $0.5 \mathrm{~mm}$ from the optic disk using previously reported methods. ${ }^{34,60}$ Animals were analyzed at 3, 7,12 , or 21 days, and 1,2 , or 4 months after the axotomy $(n=$ 8 per time point). As controls, 2 - and 4-month-old intact animals were used ( $n=8$ per age). The right retinas, contralateral to the injured ones, were analyzed in parallel.

\section{SD-OCT Measurements}

Animals were anesthetized and a drop of tropicamide (Tropicamida 1\%; Alcon-Cusí, S.A.) was instilled in both eyes to induce mydriasis. Eyes were kept hydrated with artificial tears and a custom-made contact permeable lens $(3.5-\mathrm{mm}$ posterior radius of curvature, 5.0-mm optical zone diameter, +5.0-diopter [D] back vertex power) was placed on the cornea to maintain corneal hydration and clarity. Then, both retinas were analyzed using SD-OCT according to the manufacturer instructions (Spectralis; Heidelberg Engineering, Heidelberg, Germany). To adapt for the rat's eye, a commercially available 78-D double aspheric fundus lens (Volk Optical, Inc., Mentor, $\mathrm{OH}$, USA) was mounted in front of the camera unit. Imaging was performed with a proprietary software package (Eye Explorer, version 3.2.1.0; Heidelberg Engineering) as described. ${ }^{61}$

Two scanning patterns centered on the optic nerve head were performed: a circular (peripapillary) B-scan with a radius of $500 \mu \mathrm{m}$ (Fig. 1) and a raster scan of 61 equally spaced horizontal B-scans spanning the central retina $(3000-\mu \mathrm{m}$ length, Fig. 2). In all of these sections, the RNFL and retinal thickness were measured using the OCT program (Fig. 1A).

For each peripapillary section, the total thickness as well as the thickness in each quadrant was obtained. Data from each raster scan (i.e., data from the 61 sections/retina) were computed (Eye Explorer, version 3.2.1.0; Heidelberg Engineering) giving back the thickness for each quadrant (dorsal, nasal, temporal, and ventral) within three areas: a circle centered in the ON with a radius of $400 \mu \mathrm{m}$, a ring from 400 to $800 \mu \mathrm{m}$ from the ON, and a second ring from 800 to $1200 \mu \mathrm{m}$ from the $\mathrm{ON}$. For convenience we have named these areas central, inner, and outer, respectively.

\section{Retinal Dissection and Immunodetection}

Rats were euthanized just after SD-OCT imaging with an IP overdose of pentobarbital (Dolethal, Vetoquinol; Especialidades Veterinarias, S.A., Alcobendas, Madrid, Spain), perfused with saline followed by $4 \%$ paraformaldehyde in PBS, and both retinas were dissected as whole-mounts by making four radial cuts, the deepest one signaling the superior pole, as reported. ${ }^{62}$ Retinal whole-mounts were subjected to Brn3a (goat anti-Brn3a diluted 1:500; C-20; Santa Cruz Biotechnologies, Heidelberg, Germany) ${ }^{63}$ and RT97 (mouse IgG1 antipNFH diluted 1:200, Clone RT-97; Serotec, Bionova, Spain) ${ }^{64-68}$ double immunofluorescence. Antibody RT97 is a monoclonal antibody that recognizes the phosphorylated heaviest subunit of the neurofilament triplet ( $\mathrm{pNFH}$ ) and whose abnormal expression is an index of axonal injury. ${ }^{34,44,67-73}$ In the present 


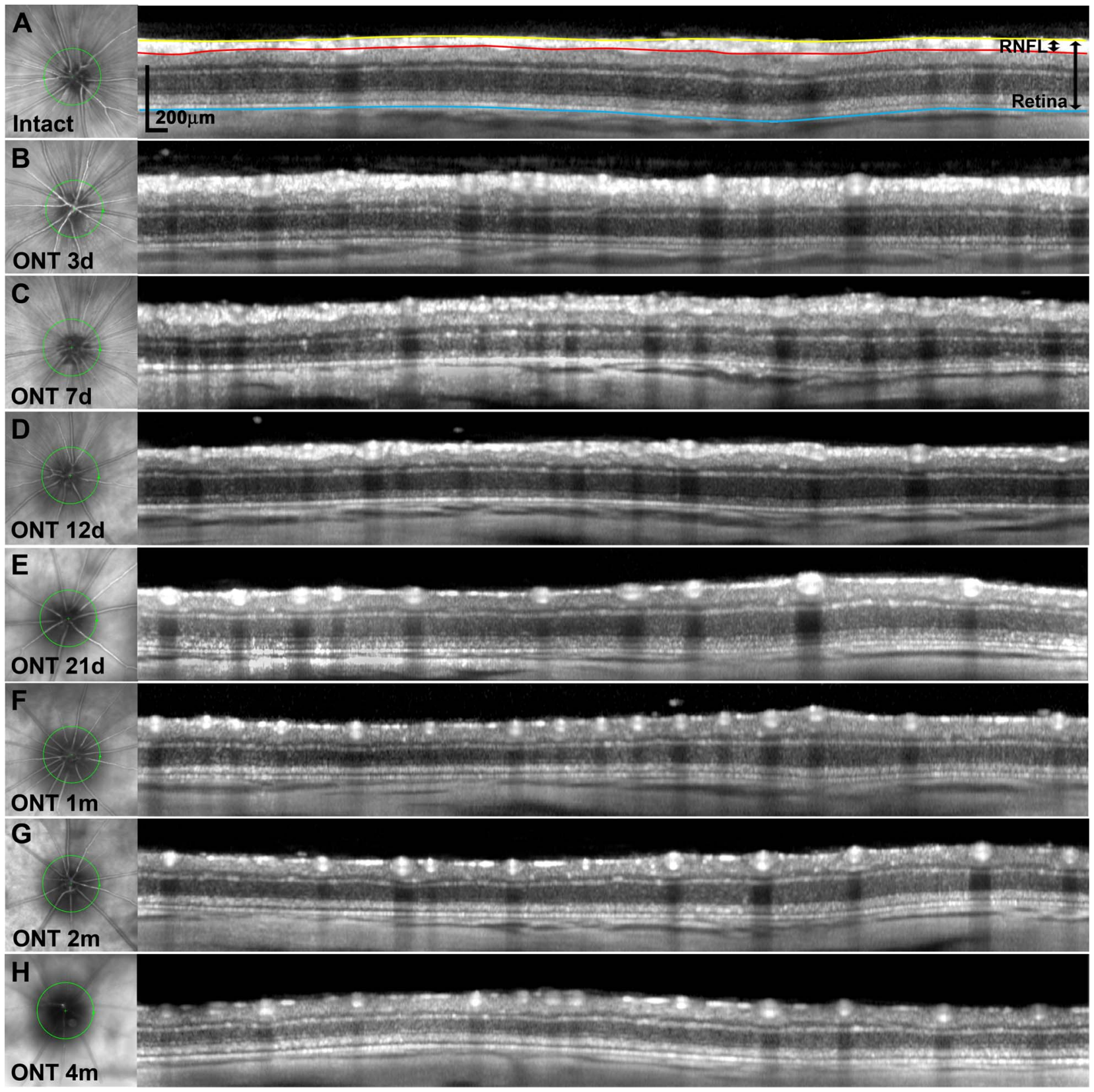

Figure 1. Representative images from the in vivo SD-OCT peripapillary analysis. (A) Intact retina. (B-H) Retinas analyzed from 3 days to 4 months after IONT. At the left of each row is shown the ocular fundus and the green circle marks where the circular section was taken from. In these images is observed a clear change in the RNFL from 21 days onwards. Segmentation of the inner limiting membrane (yellow), outer border of the nerve fiber layer (red), and pigment epithelium (blue) were used to determine measurements of peripapillary RNFL thickness and whole retinal thickness.

studies, we have identified Brn3a $\mathrm{a}^{+}$RGCs in the GCL, which account for the immense majority of the RGC population in the albino rat retina. ${ }^{2,41,62,63,74}$ This approach, however, does not take into account the small populations of melanopsin ${ }^{+}$ intrinsically photosensitive RGCs nor one-half of the ipsilaterally projecting RGCs (which do not stain with Brn3a and account for approximately $2.5 \%$ or $0.5 \%$, respectively, of the RGC population), nor the small subpopulation of displaced RGCs to the inner retina (approximately 0.5\%). ${ }^{2,63}$ Secondary detection was sequentially done using first donkey anti-goat Alexa Fluor 568 and secondly goat anti-mouse IgG1 Alexa Fluor 488 (1:500; Molecular Probes ThermoFisher, Madrid, Spain). Finally, all retinas were mounted vitreal side up with anti-fading medium.

\section{Image Acquisition, RGC Quantification, and Topography}

Retinal whole mounts were photographed under an epifluorescence microscope, while $\mathrm{Brn}_{3} \mathrm{a}^{+} \mathrm{RGCs}$ and $\mathrm{pNFH}^{+}$axons were photographed in the same retinas. Individual frames (154/retina) were later reconstructed as retinal photomontages as previously reported. ${ }^{26,62}$ The total number of $\mathrm{Brn} 3 \mathrm{a}^{+}$RGCs was automatically quantified (image analysis software: ImagePro Plus, IPP 5.1 for Windows; Media Cybernetics, Silver Spring, MD, USA) using established routines by our group. ${ }^{41,74}$ The topography of $\mathrm{Brn}_{3} \mathrm{a}^{+} \mathrm{RGCs}$ was assessed using isodensity and neighbor maps as reported..$^{2,74}$ 


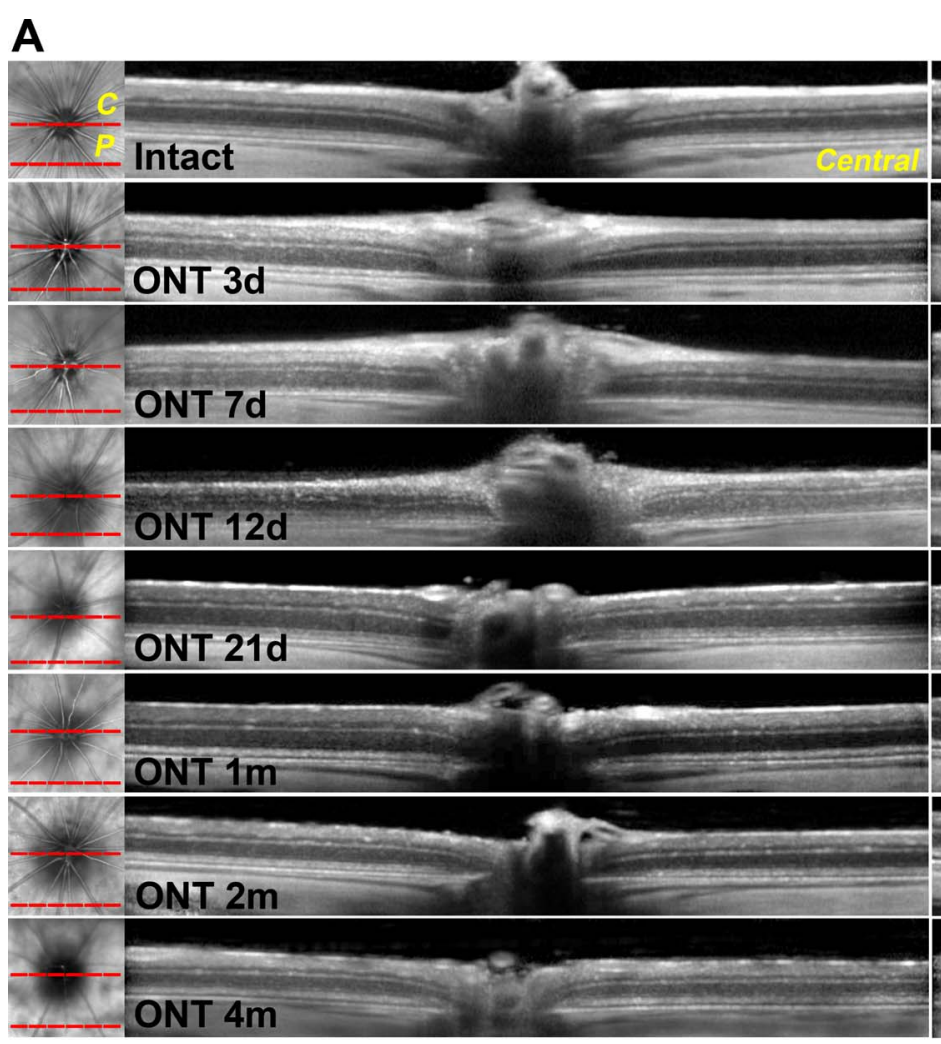

\section{B}

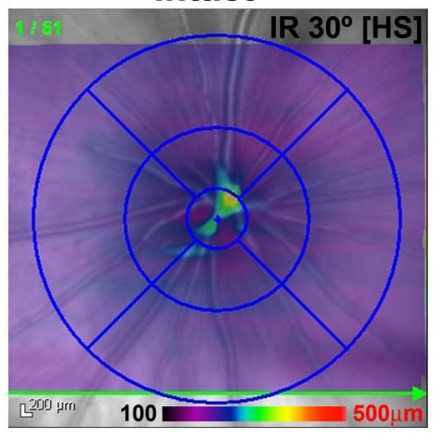

ONT 21d

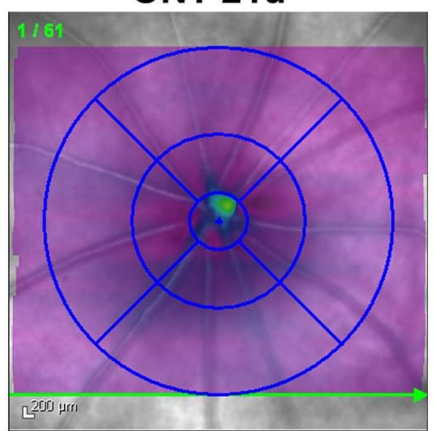

ONT 3d

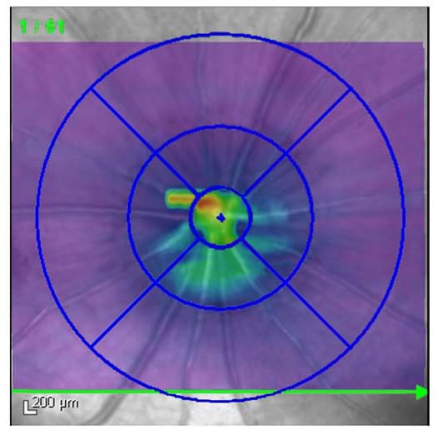

ONT $1 \mathrm{~m}$

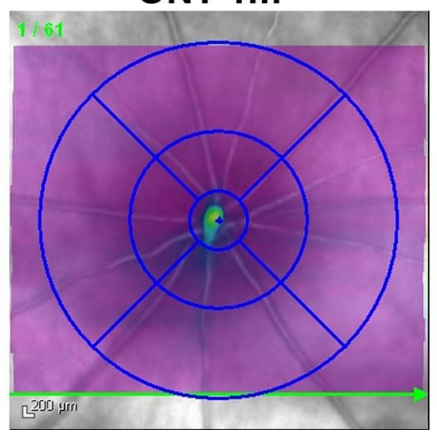

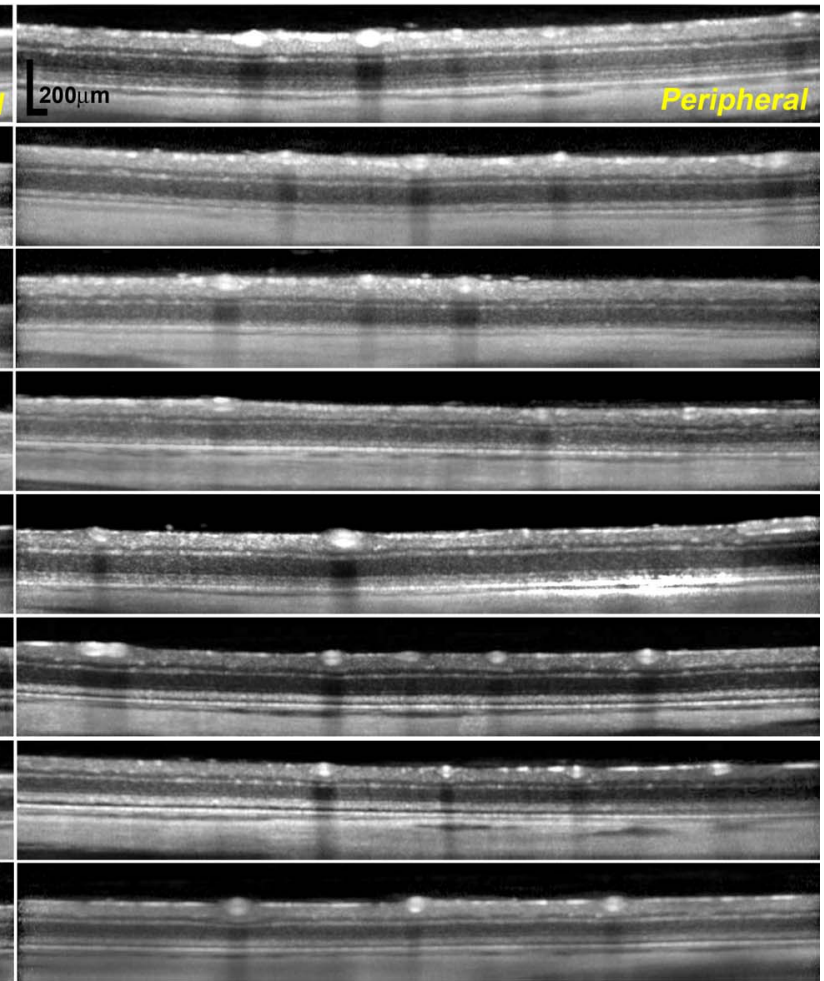

ONT 7d

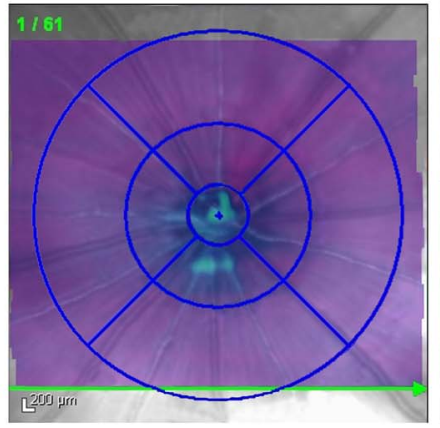

ONT $2 \mathrm{~m}$

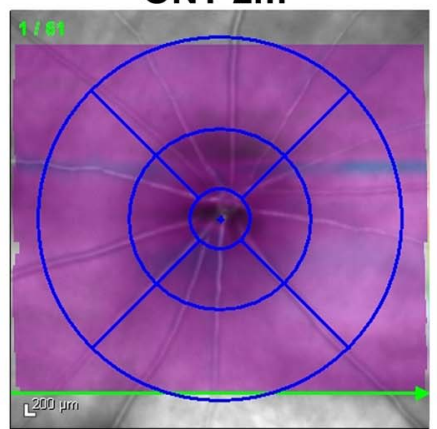

ONT 12d

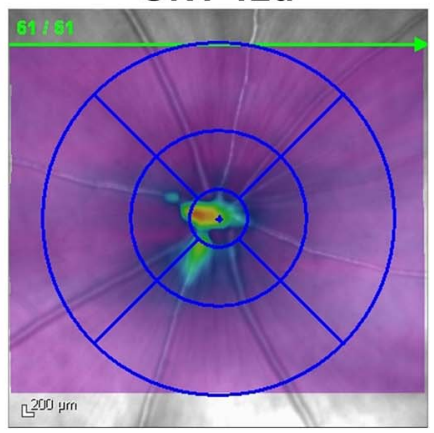

ONT $4 \mathrm{~m}$

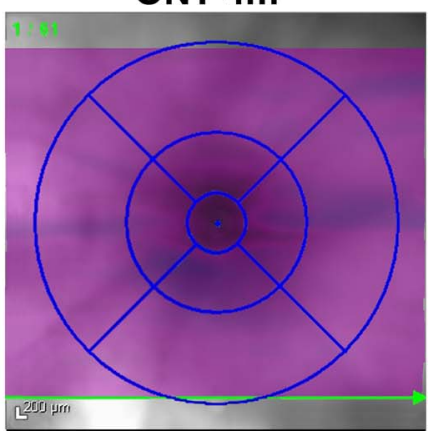

Figure 2. Representative images from the in vivo OCT volume scan analysis. (A) In each row is shown the ocular fundus image (left) and a central $(C)$ and peripheral $(P)$ section from the B-scan. (B) Volumetric analysis of the RNFL thickness. In the central retina the RNFL swells from 3 to 12 days, and thereafter thins (color scale in top left).

\section{Statistics}

Data are shown as the mean \pm SD. Because in the OCT measurements there were no differences between the dorsal/ temporal/nasal and ventral retinal quadrants, data were pulled together and shown as a whole. Pairwise multiple comparisons (ANOVA or Kruskal-Wallis ANOVA and post hoc tests Tukey or Dunn) were done with GraphPad Prism v. 6 software (GraphPad, San Diego, CA, USA). Differences were considered significant when $P<0.05$. 
TABLE 1. OCT Measurements

\begin{tabular}{|c|c|c|c|c|}
\hline & \multirow[b]{2}{*}{ Peripapillary } & \multicolumn{3}{|c|}{ Volume Scan } \\
\hline & & Central & Inner & Outer \\
\hline \multicolumn{5}{|l|}{ RFNL thickness, $\mu \mathrm{m}$} \\
\hline Intact 2 months old, $n=16$ & $43 \pm 6$ & $54 \pm 17$ & $46 \pm 6$ & $35 \pm 3$ \\
\hline Intact 4 months old, $n=16$ & $38 \pm 6$ & $49 \pm 15$ & $41 \pm 7$ & $33 \pm 3$ \\
\hline Contralateral retinas, $n=48$ & $39 \pm 5$ & $52 \pm 8$ & $42 \pm 8$ & $32 \pm 4$ \\
\hline Intact + contralateral, $n=84$ & $40 \pm 7$ & $51 \pm 12$ & $41 \pm 8$ & $32 \pm 4$ \\
\hline \multicolumn{5}{|l|}{ ONT, $n=8 /$ time } \\
\hline $3 \mathrm{~d}$ & $39 \pm 4$ & $63 \pm 11^{*}$ & $48 \pm 6$ & $32 \pm 3$ \\
\hline $7 \mathrm{~d}$ & $38 \pm 3$ & $67 \pm 15^{*}$ & $45 \pm 7$ & $27 \pm 3^{*}$ \\
\hline $12 \mathrm{~d}$ & $36 \pm 2 \dagger$ & $65 \pm 23 \dagger$ & $41 \pm 7$ & $27 \pm 3^{*}$ \\
\hline $21 \mathrm{~d}$ & $19 \pm 2 \neq \delta$ & $36 \pm 6^{*} \Phi$ & $25 \pm 3 \neq \varnothing$ & $20 \pm 1 \neq \varnothing$ \\
\hline $1 \mathrm{~m}$ & $22 \pm 2 \ddagger$ & $37 \pm 17 \dagger$ & $26 \pm 4 \neq$ & $21 \pm 3 \ddagger$ \\
\hline $2 \mathrm{~m}$ & $15 \pm 2 \neq \varnothing$ & $20 \pm 13+\|$ & $24 \pm 6 \neq$ & $20 \pm 3 \ddagger$ \\
\hline $4 \mathrm{~m}$ & $11 \pm 2 \ddagger$ & $9 \pm 1 \neq \|$ & $13 \pm 4 \neq \rrbracket$ & $15 \pm 1 \neq \uparrow$ \\
\hline \multicolumn{5}{|l|}{ Retinal thickness, $\mu \mathrm{m}$} \\
\hline Intact 2 months old, $n=16$ & $222 \pm 13$ & $303 \pm 69$ & $227 \pm 13$ & $210 \pm 6$ \\
\hline Intact 4 months old, $n=16$ & $210 \pm 12$ & $295 \pm 60$ & $211 \pm 14$ & $202 \pm 8$ \\
\hline Contralateral retinas, $n=48$ & $212 \pm 10$ & $282 \pm 18$ & $212 \pm 14$ & $203 \pm 8$ \\
\hline Intact + contralateral, $n=84$ & $212 \pm 14$ & $281 \pm 72$ & $213 \pm 15$ & $203 \pm 10$ \\
\hline \multicolumn{5}{|l|}{ ONT, $n=8 /$ time } \\
\hline $3 \mathrm{~d}$ & $208 \pm 15$ & $300 \pm 65$ & $224 \pm 17$ & $201 \pm 8$ \\
\hline $7 \mathrm{~d}$ & $211 \pm 11$ & $272 \pm 36$ & $214 \pm 14$ & $194 \pm 8^{*} \mid$ \\
\hline $12 \mathrm{~d}$ & $208 \pm 14$ & $312 \pm 43$ & $211 \pm 21$ & $191 \pm 9^{*}||$ \\
\hline $21 \mathrm{~d}$ & $191 \pm 15^{*} \|$ & $257 \pm 57$ & $193 \pm 22^{*}$ & $193 \pm 6^{*}||$ \\
\hline $1 \mathrm{~m}$ & $181 \pm 7 \ddagger||$ & $247 \pm 55$ & $198 \pm 17^{*}$ & $190 \pm 11^{*}$ \\
\hline $2 \mathrm{~m}$ & $172 \pm 7 \ddagger||$ & $229 \pm 64 * \mid$ & $192 \pm 17 \ddagger$ & $191 \pm 9^{*} \mid$ \\
\hline $4 \mathrm{~m}$ & $169 \pm 7 \ddagger$ & $208 \pm 9 \ddagger \|$ & $175 \pm 11 \neq||$ & $178 \pm 4 \neq \|$ \\
\hline
\end{tabular}

Retinal nerve fiber layer (top) and retinal (bottom) thickness ( $\mu \mathrm{m}$, mean \pm SD) measured using the peripapillary tool (circular section at 500- $\mu \mathrm{m}$ radius from the $\mathrm{ON}$ ) and the volume scan tool (center, from 0-400, inner from 400-800, and outer from 800-1200 $\mu \mathrm{m}$ ). There were no statistically significant differences between retinas from 1- and 4-month-old intact animals, nor between intact retinas and right retinas contralateral to the injured ones. Thus, intact + contralateral retinas were used as control.

* Significant compared to control (ANOVA Kruskal-Wallis, $P<0.01$ ).

† Significant compared to control (ANOVA Kruskal-Wallis, $P<0.05$ ).

‡ Significant compared to control (ANOVA Kruskal-Wallis, $P<0.001$ ).

S Significant compared to the previous time point (ANOVA Kruskal-Wallis, $P<0.001$ ).

|| Significant compared to the previous time point (ANOVA Kruskal-Wallis, $P<0.05$ ).

If Significant compared to the previous time point (ANOVA Kruskal-Wallis, $P<0.01$ ).

\section{RESUlts}

\section{In Vivo Analysis of the Retina and RNFL}

Representative examples of the SD-OCT images acquired using the peripapillary B-scan and the raster scan (61 sections) from each animal group are shown in Figures 1 and 2, respectively. There were no differences in the whole retinal and RNFL thickness between 2- and 4-month-old intact animals, although the latter were slightly thinner (Table 1 ). The measurements obtained for the fellow (contralateral to the injured) retinas were comparable to intact retinas. Thus, these values (intact + contralateral) were averaged and used as control.

In the RNFL, the first significant changes following IONT are observed with the volume scan analysis; from 3 to 12 days the RNFL in the central area is swollen because it is thicker than in control retinas (Table 1 ; Fig. 3A). The peripapillary tool disclosed a small (10\%), but significant, reduction of the RNFL at 12 days. From 21 days onwards, there was a significant decrease of the RNFL in all analyses, and at 4 months between $53 \%$ (outer) to $82 \%$ (central) of the RNFL thickness has disappeared (Table 1; Fig. 3A). The peripheral RNFL (volume scan, outer) is significantly thinner already at 7 days; at 21 days there is a further significant decrease and by 4 months it is reduced by $53 \%$ (Table 1 ).
After IONT, the whole retinal thickness shows the first significant thinning of $4 \%$ at 7 days in the outer, most peripheral, region that does not progresses significantly until 4 months, when the diminution reaches $12 \%$. In the rest of analysis, the retina thins significantly at day 21 after IONT except for the central volume scan where the first significant decrease occurs at 2 months (Table 1). By 4 months, the retinal thickness has diminished to $80 \%, 74 \%, 82 \%$, and $88 \%$ of their control values for the peripapillary, central, inner, and outer areas, respectively (Table 1 ).

\section{Ex Vivo Analysis of the RNFL}

To correlate in vivo imaging measurements with ex vivo appearance of the RNFL, we examined the expression of pNFH in each retinal whole mount. The fellow control retinas showed typical pNFH signal of the most distal portion of the intraretinal axons within the middle and central retina where they converge into axonal bundles and form the ON head (Fig. $\left.4 A^{\prime}\right)$. These axons were uniformly labeled and their morphology is rectilinear; very rarely an axon was stained to the retinal periphery or was the cell soma decorated with pNFH immunoreactivity. In agreement with a previous report, ${ }^{26}$ following IONT the experimental retinas examined 3 or 7 days 
A

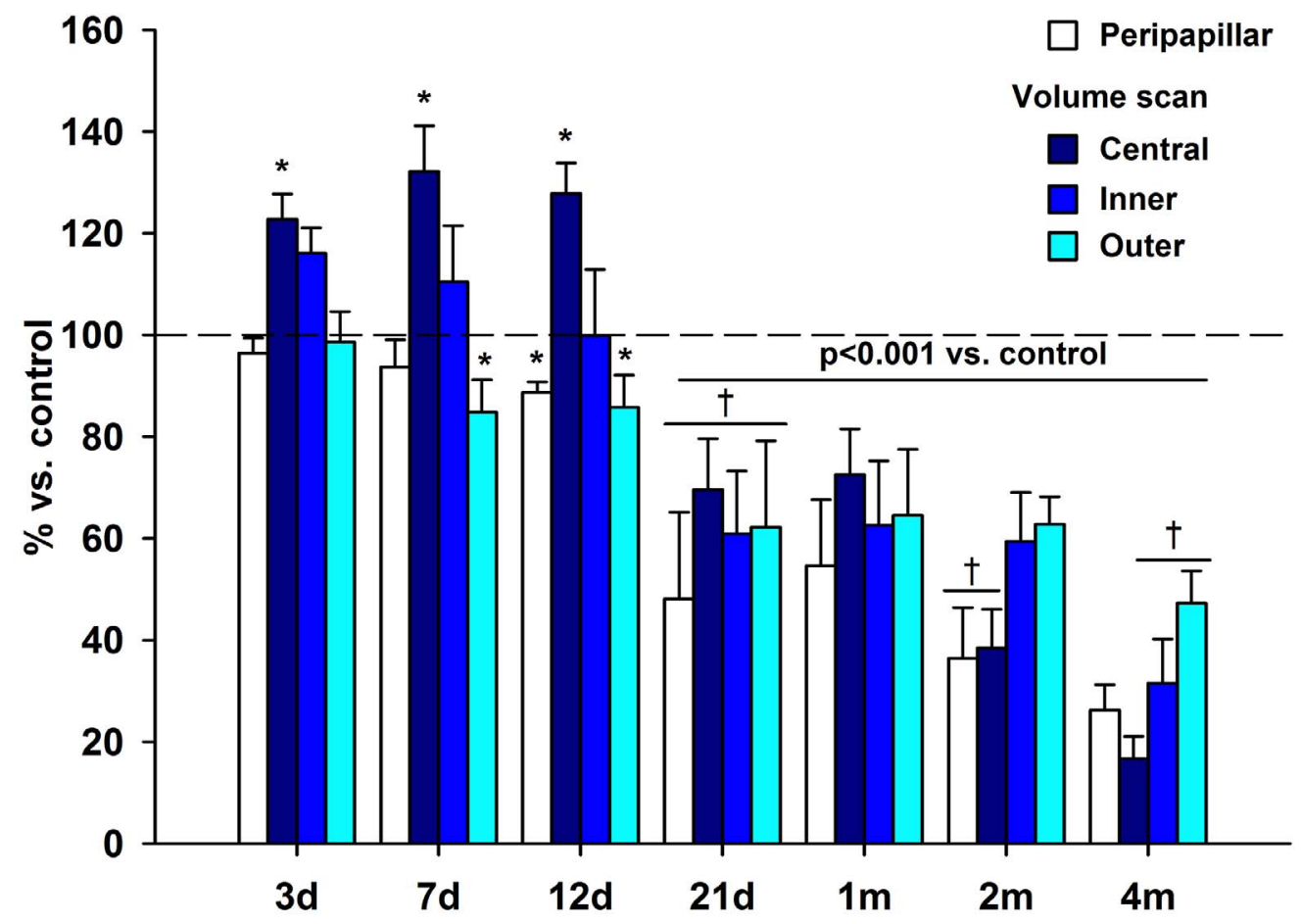

B

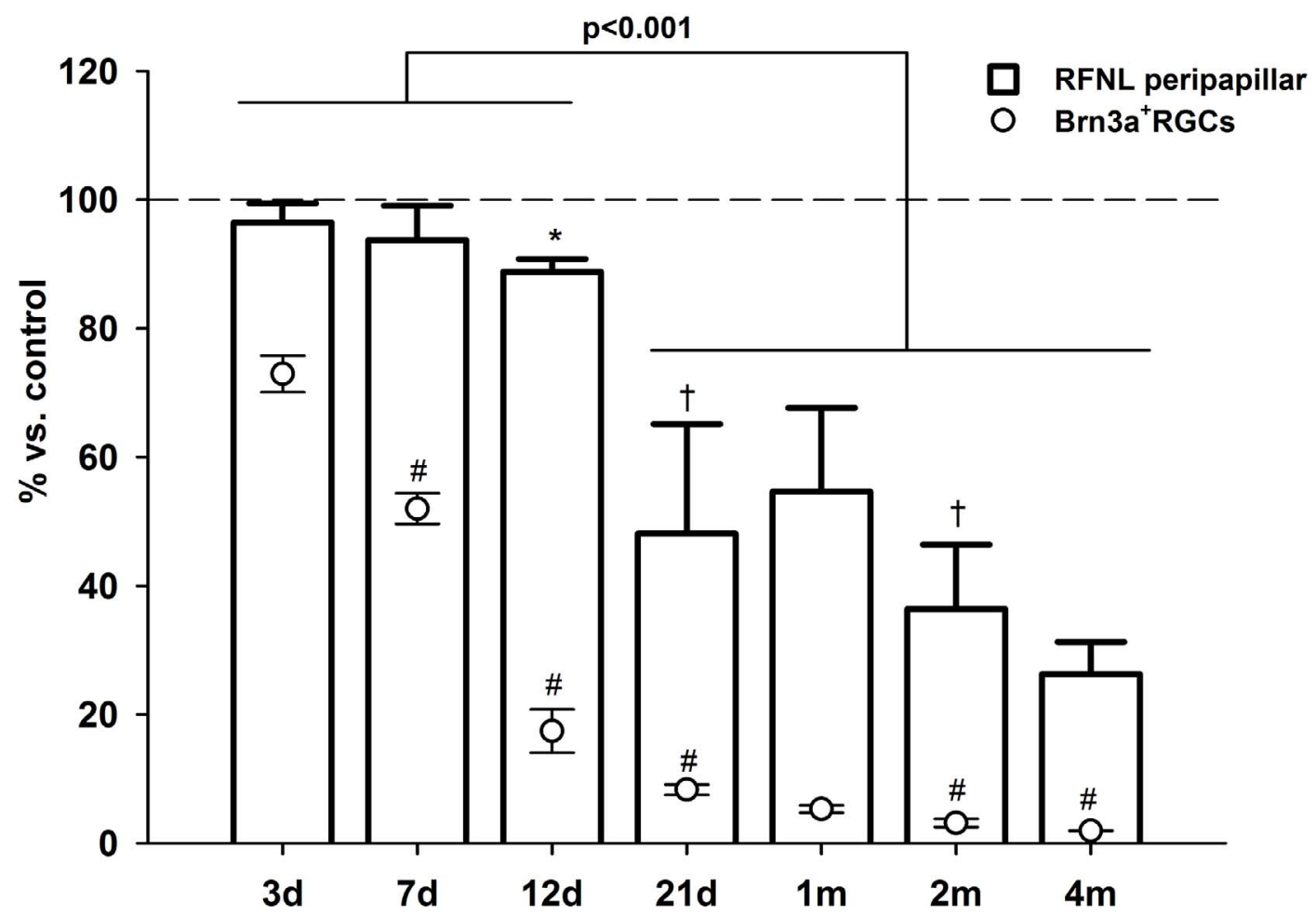

Figure 3. Retinal nerve fiber layer thinning and surviving RGCs after ONT. Histogram showing the RNFL thickness as a percent of the values in intact and right retinas (borizontal line, 100\%) for volume scan and peripapillary scan (A), and peripapillary alone (B). (B) White circles represent the percent of surviving RGCs in the same retinas at the same time points. "Significant compared to control. $\dagger \#$ Significant compared to the previous time point. 

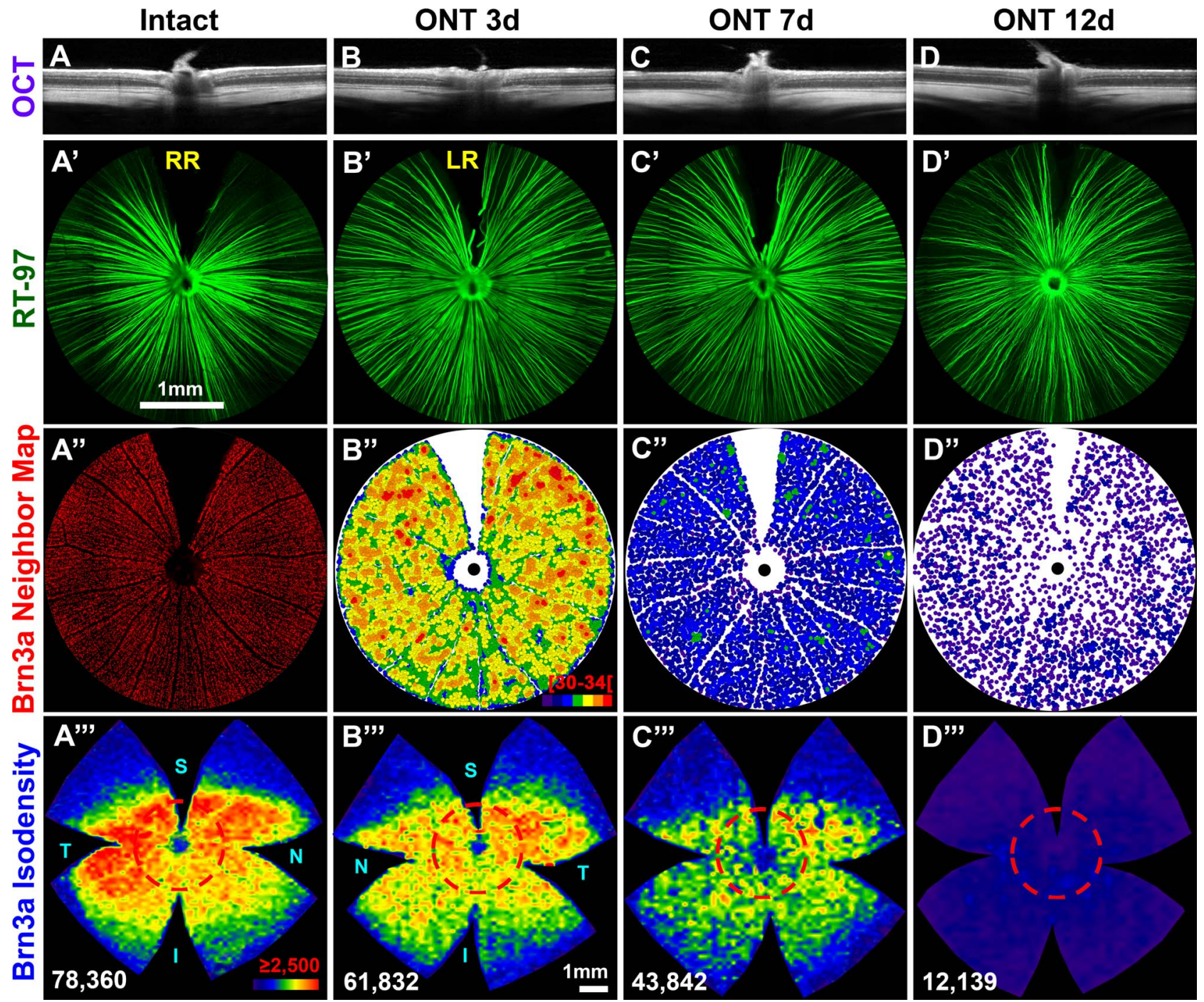

Figure 4. Degeneration of the RNFL and RGC loss from 3 to 12 days after ONT. (A-D) Shown are SD-OCT sections across the optic disk of an intact retina (A) and from retinas analyzed 3 (B), 7 (C) or 12 (D) days after IONT. (A'-D') Shown is pNFH signal in the central retina from the same retinas as (A-D). (A"-D") Shown are Brn3a+ RGCs in the same area as (A'-D'). (A") Actual signal of Brn3a, in (B"-D") Brn3a ${ }^{+}$RGCs are represented with the nearest neighbor algorithm, allowing a clear view of their density and gradual loss along time post lesion in the central retina (red circles in isodensity maps, last row). (A"'-D"') Brn3a $\mathrm{a}^{+}$RGCs isodensity maps from the same retinas as above, showing the total loss of RGCs. At the bottom of each map is shown the total number of Brn3 $\mathrm{a}^{+}$RGCs counted in each retina. Neighbor maps color scale in (B"): each color represents an increase of four neighbors in a radius of $0.0552 \mathrm{~mm}$ from purple (0-4 neighbors) to red ( $\geq 30-34$ neighbors). Isodensity map color scale (A"') goes from 0 cells/

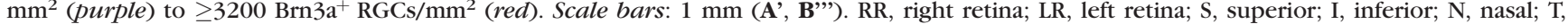
temporal.

later did not show noticeable changes in their pNFH expression (Figs. 4B', 4C'), except for the pNFH labeling to the most proximal part of the RGC axon, which was evident in the retinal periphery. In contrast, the retinas examined 12 (Fig. 4D') or 21 (Fig. 5A') days after IONT showed abnormal staining consisting of accumulations of pNFH staining material in the form of rosary beads or varicosities along degenerating axons, as well as an intense staining of the soma and primary dendrites in a small number of $\mathrm{RGCs}\left(\mathrm{pNFH}^{+} \mathrm{RGCs}\right)$. From 21 days onward there were fewer visible $\mathrm{pNFH}^{+} \mathrm{RGCs}$. The loss of RGC axons was barely observable in the central regions of the retina at 12 days, became evident at 21 days, and progressed with increasing survival intervals up to 4 months after IONT, the latest time point examined in the present study (Figs. 4A'$\left.\mathrm{D}^{\prime}, 5 \mathrm{~A}^{\prime}-\mathrm{D}^{\prime}\right)$. This is illustrated for the central region of a representative retina for each group analyzed, the same region that also was measured in vivo with SD-OCT (Figs. 4, 5).

\section{RGC Survival}

The fellow right control retinas showed the typical $\mathrm{Br}_{3} \mathrm{a}^{+} \mathrm{RGCs}$ distribution across the retina; they were denser in the medial and central retina and sparser in the periphery, with higher densities in the visual streak located in the dorsal retina approximately $1 \mathrm{~mm}$ above the optic disc and peak densities in the superior-temporal retina (Figs. 4A"-A"), in agreement with previous reports. ${ }^{41,62,75}$ Moreover, automatic counts of $\mathrm{Brn} 3 \mathrm{a}^{+}$ RGCs showed total numbers in the naïve control retinas (aged 2 or 4 months, $n=16$ ) that were comparable to those found in the right fellow retinas $(n=56)$, and these values also were comparable to our previously reported data. ${ }^{2,62,74,76}$ Thus, 


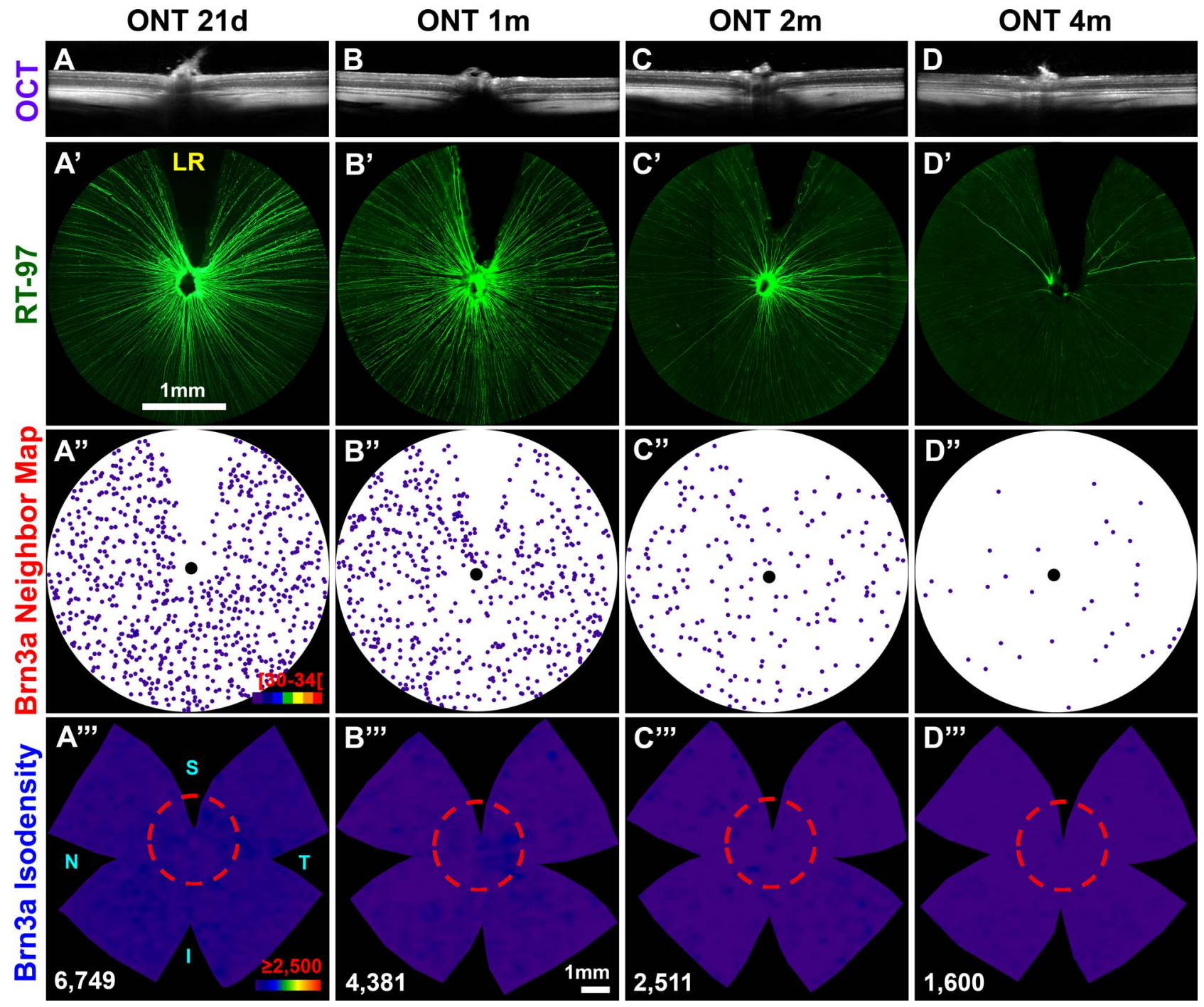

Figure 5. Degeneration of the RNFL and RGC loss from 21 days to 4 months after ONT. (A-D) Sections obtained by SD-OCT across the optic disk from retinas analyzed at 21 days $(\mathbf{A})$ and 1 (B), 2 (C), or 4 (D) months after ONT. (A'-D') A pNFH signal in the central retina from the same retinas as (A-D). (A"-D") Shown are Brn3a+ RGCs in the same area as (A'-D'). (A") The actual signal of Brn3a; in (B"-D") Brn3a+RGCs are represented with the nearest neighbor algorithm, allowing a clear view of their density and gradual loss along time post lesion in the central retina (red circles in isodensity maps, last row). (A"'-D'") Shown are Brn3a+ RGCs isodensity maps from the same retinas as above, showing the total loss of RGCs. At the bottom of each map is shown the number of Brn3 $\mathrm{a}^{+} \mathrm{RGCs}$ counted in each retina. Neighbor maps color scale in (B"): Each color represents an increase of four neighbors in a radius of $0.0552 \mathrm{~mm}$ from purple (0-4 neighbors) to red ( $\geq 30-34$ neighbors). Isodensity map color scale (A"') goes from 0 cells/ $/ \mathrm{mm}^{2}$ (purple) to $\geq 3200 \mathrm{Brn} 3 \mathrm{a}^{+} \mathrm{RGCs} / \mathrm{mm}^{2}$ (red). Scale bars: $1 \mathrm{~mm}$ (A', B'").

these values were pulled together $(2$ and 4 months controls + right fellow retinas), averaged, and used as control (Table 2).

In the experimental retinas, a significant diminution in total numbers of $\mathrm{Br}^{3} \mathrm{a}^{+} \mathrm{RGCs}$ to $71 \%$ of the original RGC population was observed 3 days after IONT (Table 2; Figs. 3B, 4, 5). Survival of RGCs decreased to approximately $52 \%, 17 \%$, and $9 \%$ by 7,12 , and 21 days after IONT, respectively. There were further decreases at increasing survival intervals, and at 4 months only approximately $2 \%$ of the original RGC population survives (Table 2; Figs. 3B, 4, 5). Thus, total counts of RGCs showed, from 3 days onwards, a progressive RGC loss with a typical temporal course previously reported. ${ }^{30,41,45}$ Moreover, a detailed analysis of the topography of RGC loss in the isodensity maps indicates that RGC loss is diffuse throughout the retina and does not show a sectorial pattern. There were greater losses in areas of the retina with higher RGC densities (Figs. 4, 5), as reported. ${ }^{23,40,43}$

\section{Comparison of the In Vivo and Ex Vivo}

\section{Appearance of the Retinal NFL With RGC Counts}

To correlate the in vivo measurements of the RNFL with its ex vivo appearance and RGC survival, we have compared the peripapillary measurements with the appearance of the nerve fiber layer stained for neurofilaments and with total numbers of Brn $3 \mathrm{a}^{+}$RGCs, for each retina at each survival interval. Following IONT there was progressive RGC loss and RNFL thinning was progressive, as expected from the retrograde degeneration that follows axonal injury. However, there was a time lapse between the onset of these two progressive degenerative events. While RGC loss was already evident by day 3 after IONT, the first significant SD-OCT thinning of the RNFL was observed at 12 days (Fig. 3B) and this also was the first time point when RT97 stained whole mounts exhibited a clear diminution in axonal density (Fig. 4). At 21 days, the RNFL showed significant thinning measured with SD-OCT 
TABLE 2. Number of Brn3a $a^{+}$RGCs

\begin{tabular}{|c|c|c|c|c|c|c|c|c|c|c|}
\hline & \multirow[b]{2}{*}{ Intact, $2 \mathrm{~m}$} & \multirow[b]{2}{*}{ Rigth Retinas } & \multirow[b]{2}{*}{ Intact \& RR } & \multicolumn{7}{|c|}{ ONT } \\
\hline & & & & $3 d$ & $7 \mathrm{~d}$ & $12 \mathrm{~d}$ & $21 \mathrm{~d}$ & $1 \mathrm{mo}$ & $2 \mathrm{mo}$ & $4 \mathrm{mo}$ \\
\hline Mean & $\begin{array}{c}n=16 \\
79.487\end{array}$ & $\begin{array}{c}n=56 \\
79.752\end{array}$ & $\begin{array}{c}n=72 \\
79.613\end{array}$ & $\begin{array}{c}n=8 \\
56.570\end{array}$ & $\begin{array}{l}n=8 \\
41.753^{*}\end{array}$ & $\begin{array}{l}n=8 \\
13.299^{*}\end{array}$ & $\begin{array}{c}n=8 \\
6.780^{*}\end{array}$ & $\begin{array}{r}n=8 \\
4.30\end{array}$ & $\begin{array}{c}n=8 \\
2.360 \dagger\end{array}$ & $\begin{array}{l}n=8 \\
1.644 \ddagger\end{array}$ \\
\hline SD & 4173 & 2838 & 2875 & 3129 & 2257 & 2636 & 589 & 371 & 553 & 331 \\
\hline
\end{tabular}

Mean \pm SD of Brn $3 \mathrm{a}^{+}$RGCs in naive retinas, right retinas (RR) contralateral the injured ones, and in the injured retinas from 2 days to 4 months after the axotomy (ONT). The number of surviving RGCs is at all time points significantly smaller than in control retinas (intact $\&$ contralateral, ANOVA Tukey $t$-test $P<0.001$ ).

* Significant difference compared to the previous time point, $P<0.01$.

† Significant difference compared to the previous time point, $P<0.001$.

¥ Significant difference compared to the previous time point, $P<0.05$.

(52.5\% decrease), and microscopic examination showed a clear diminution in the numbers of intraretinal RGC axons within the central region of the retinal whole mounts, but only $8.5 \%$ of the RGC population survived in the retina (Figs. 3B, 4, 5). At increasing survival intervals of 2 or 4 months after IONT, thinning of the RNFL became more evident (63\% and $72.5 \%$ decrease, respectively), and this also was the case when whole mounts stained for neurofilaments were observed under the microscope, but at these time intervals of 2 or 4 months, only a minute proportion of $3 \%$ or $2 \%$, respectively, of the original RGC population was alive.

\section{Discussion}

We compared the time-course and severity of retrograde degeneration of the RGC population and their intraretinal axons following IONT in adult albino rats. While both degenerative events progress in a time-dependent manner, there are several differences: There is a delay of approximately 9 days between the time that RGC loss and RNFL thinning first become evident; there is a mismatch, particularly evident for the early time intervals after IONT, between the magnitude of the RGC loss and that of RNFL thinning; and the severity of RGC loss appears much greater than that of RNFL thinning.

\section{Retrograde Degeneration of RGCs and Their Intraretinal Axons Have Different Onset Times}

The onset of an evident RGC loss or RNFL thinning is separated by a time lapse of approximately 9 days based on RGC counts and the quantitative data obtained from the peripapillary ring or the measurements obtained from the center and middle rings of the volume scan. A similar observation was drawn when the nerve fiber layer was assessed qualitatively on RT97-stained whole mounts, because loss of intraretinal axons was first evident at 12 days after IONT (Figs. 4, 5). However, total RGC counts indicate by 3 days a significant reduction of $29 \%$ (Fig. 3; Table 2). In the present studies, we did not quantify the level of RT97 expression within the NFL; this was reported in a previous study in albino rats following the same insult and examined at 3-, $7-, 14-, 21-$, or 30 -day intervals. ${ }^{26}$ In this study, the fluorescent area of the central ring (a ring with a radius of one-third the normal retinal radius that had excluded the optic disc) showed a decrease in RT97 immunofluorescence with time after IONT; the decrease was not apparent at 3 or 7 days, but was first significant at 14 days and progressed up to 30 days, the latest time point quantified in those studies (see Fig. 9, reported previously ${ }^{26}$ ). While in naïve retinas RT97+ axons occupy $61 \%$ of the central area, 14 days after IONT this value decreased to $40 \%$, and by 30 days it had further decreased to $14 \%$. Overall, these results indicated that at early stages after IONT, neither the thickness nor the appearance of the retinal NFL is an accurate index of RGC survival. Moreover, the time lapse between the onset of RGC and RNFL degeneration adds further evidence toward the concept that following IONT, RGC death precedes intraretinal RGC axonal degeneration. ${ }^{15,16,26,50,51,56-58}$

\section{Mismatch in RGC Loss and RNFL Thinning at Early Survival Intervals}

Following IONT, the NFL thinning and RGC loss showed a progressive decline with time, and this is in agreement with previous studies that have studied RGC loss $23,40,41,43,50$ or nerve fiber layer thinning $49,50,54,55$ by separate or in the same rodents. ${ }^{51,56,57}$ Our results also indicated discrepancies between the numbers of surviving RGCs and the thickness and appearance of the RNFL at specific survival intervals. This mismatch was evident not only for the early time intervals after IONT, as previously reported for pigmented mice $\mathrm{e}^{50,56,57}$ and rats, ${ }^{51}$ but also for longer survival intervals. For example, at 12 days, the first time that the RNFL shows significant (10\%) thinning, only $17 \%$ of the original RGC population survives in the retina, and by 21 days the RNFL has decreased to $48 \%$ of its normal value, while only $8.5 \%$ of the original RGC population survives in the retina. By two months, the RNFL shows $37 \%$ of its normal thickness, but the RGC population only amounts to $3 \%$. The disparities observed between RNFL thickness and RGC densities at early time points in the present studies may have been underscored by the fact that we used Brn3a rather than retrogradely transported Fluorogold (FG) to identify and count surviving RGCs. The Brn3a may be used to identify injured but viable $\mathrm{RGCs}^{43}$ because its expression does not disappear immediately after IONT, but just before Caspase 3 activation, ${ }^{77}$ and, thus, Brn3a expression disappears earlier than the carcass of the FG-labeled RGC, which needs activation of microglia and phagocytosis of the debris and this requires some time. Therefore, when RGC loss is examined with Brn3a versus FG, there is a shift toward earlier times. ${ }^{41,64}$ Overall, these results indicated that SD-OCT can monitor accurately neurodegeneration of the rat RNFL following IONT, but one should be aware of the differences between these two phenomena, the RGC loss and the RNFL thinning, when extrapolating or using RNFL information as a surrogate for RGC survival, because the amount of intraretinal axonal loss does not match exactly the magnitude of RGC loss.

\section{The Magnitude of RGC Degeneration Appears Greater Than That of Intraretinal Axons}

The severity of RGC loss appears much greater than that of RNFL thinning, that is, RGC counts indicate that approximately $2 \%$ of the RGC population survives in the retina at 4 months after IONT, and while RT97-stained whole mounts showed very few axons remaining in the RNFL, the SD-OCT measure- 
ments indicated a maximal reduction of the RNFL to approximately $27.5 \%$ of its control value. One could expect a similar magnitude in RNFL thickness reduction as that of RGCs, but it is possible that other nonneuronal structures within the RNFL, such as invading and/or migrating microglia responsible for the clearance of axonal debris, ${ }^{78,79}$ a macroglia gliosis, ${ }^{80}$ and the presence of vascular cells may account for an important part of the volume of the RNFL that remains even after the vast majority of RGCs and their axons have degenerated.

\section{Transient Thickening of the RNFL}

Our RNFL thickness measurements of the central ring (volume scan) indicated a transient thickening in close proximity to the optic disc from 3 to 12 days after IONT that became significantly thinner by 21 days. A similar event also has been observed following acute IOP elevation ${ }^{52}$ or chronic OHT ${ }^{81}$ and could well be explained by a transient general inflammatory response following ON injury ${ }^{78,80,82}$ that may include macro $^{80}$ and microglial proliferation in the nerve fiber layer. $^{23-25}$ In addition, following ON injury, anterograde transport is halted ${ }^{11,83}$ at the level of the ON head, and this also may contribute to this transient thickening.

\section{Conclusions}

Among the techniques that permit the in vivo analysis of the thickness of the retinal layers, including the RNFL, is SDOCT. ${ }^{50,51,56,57}$ This technique is useful to study retinal diseases in rodent models with a precision of several micrometers, ${ }^{58,59,84-87}$ and allows longitudinal studies, that is, the possibility to track and monitor changes in the retina over time within the same individuals, thus reducing the numbers of experimental animals needed to obtain data. ${ }^{61}$ Our results in adult albino rats add new data toward the interpretation of the RNFL thickness as a surrogate for RGC survival following IONT, and are in agreement with those reported at earlier time intervals for adult pigmented rats ${ }^{51}$ and mice. ${ }^{50,56,57}$ The type of insult inflicted in the present studies (IONT) results in rapid devastating effects in the RGC population. This may differ in other situations in which RGC axons are injured farther from the ON head, and, thus, degeneration is much slower, ${ }^{45}$ or in which retinal axons are crushed rather than divided because the type of lesion has important implications in the time course and severity, not only of RGC loss, but of axonal degeneration within the RNFL, which is greater and quicker after IONT than after IONC. ${ }^{17,18,26}$

In summary, the present work demonstrated that, following IONT in adult rats, there is a time lapse between the disappearance of the RGCs and their intraretinal RGC axons, indicating that the appearance of the NFL of the retina does not reflect the actual amount of RGC survival and suggesting that RNFL degeneration is a late stage in the process of retrograde degeneration following IONT. This should be borne in mind when assessing RGC survival based on the appearance of the NFL of the retina.

\section{Acknowledgments}

The authors thank Jose María Díaz Llopis (W.M. Bloss, S.A. Barcelona, Spain) for providing the Spectralis OCT system (Heidelberg Engineering) for these studies.

Supported by Spanish Ministry of Economy and Competitiveness: SAF-2012-38328; Instituto de Salud Carlos III-FEDER "Una manera de hacer Europa" PI13/00643, PI13/01266, and Red Temática de Investigación Cooperativa en Oftalmología RETICS: RD12/0034/ 0014 .
Disclosure: G. Rovere, None; F.M. Nadal-Nicolás, None; M. Agudo-Barriuso, None; P. Sobrado-Calvo, None; L. NietoLópez, None; C. Nucci, None; M.P. Villegas-Pérez, None; M. Vidal-Sanz, None

\section{References}

1. Resnikoff S, Pascolini D, Etya'ale D, et al. Global data on visual impairment in the year 2002. Bull World Health Organ. 2004; 82:844-851.

2. Nadal-Nicolas FM, Salinas-Navarro M, Jimenez-Lopez M, et al. Displaced retinal ganglion cells in albino and pigmented rats. Front Neuroanat. 2014;8:99.

3. Valiente-Soriano FJ, Garcia-Ayuso D, Ortin-Martinez A, et al. Distribution of melanopsin positive neurons in pigmented and albino mice: evidence for melanopsin interneurons in the mouse retina. Front Neuroanat. 2014;8:131.

4. Leoz Ortin G, Arcuate LR. Procesos regenerativos del nervio óptico y retina, con ocasión de injertos nerviosos. Trab $L a b$ Invest Biol. 1914;11:239-254.

5. Ramón y Cajal S. Estudios sobre la degeneración y regeneración del sistema nervioso. In: Hijos de Nicolás Moya. 1914: 203-217.

6. Tello F. La régénération des voies optiques. Tab Lab Invest Biol. 1914;5:237-248.

7. Alarcon-Martinez L, de la Villa P, Aviles-Trigueros M, Blanco R, Villegas-Perez MP, Vidal-Sanz M. Short and long term axotomyinduced ERG changes in albino and pigmented rats. Mol Vis. 2009; 15:2373-2383.

8. Alarcon-Martinez L, Aviles-Trigueros M, Galindo-Romero C, et al. ERG changes in albino and pigmented mice after optic nerve transection. Vision Res. 2010;50:2176-2187.

9. Dengler-Crish CM, Smith MA, Inman DM, Wilson GN, Young JW, Crish SD. Anterograde transport blockade precedes deficits in retrograde transport in the visual projection of the DBA/2J mouse model of glaucoma. Front Neurosci. 2014;8: 290.

10. Lafuente Lopez-Herrera MP, Mayor-Torroglosa S, Miralles de Imperial J, Villegas-Perez MP, Vidal-Sanz M. Transient ischemia of the retina results in altered retrograde axoplasmic transport: neuroprotection with brimonidine. Exp Neurol. 2002;178: 243-258.

11. McKerracher L, Vidal-Sanz M, Essagian C, Aguayo AJ. Selective impairment of slow axonal transport after optic nerve injury in adult rats. J Neurosci. 1990;10:2834-2841.

12. McKerracher L, Vidal-Sanz M, Aguayo AJ. Slow transport rates of cytoskeletal proteins change during regeneration of axotomized retinal neurons in adult rats. J Neurosci. 1990; 10:641-648.

13. Quigley H, Anderson DR. The dynamics and location of axonal transport blockade by acute intraocular pressure elevation in primate optic nerve. Invest Ophthalmol. 1976;15:606-616.

14. Quigley HA, Anderson DR. Distribution of axonal transport blockade by acute intraocular pressure elevation in the primate optic nerve head. Invest Ophthalmol Vis Sci. 1977; 16:640-644.

15. Salinas-Navarro M, Alarcon-Martinez L, Valiente-Soriano FJ, et al. Functional and morphological effects of laser-induced ocular hypertension in retinas of adult albino Swiss mice. Mol Vis. 2009;15:2578-2598.

16. Salinas-Navarro M, Alarcon-Martinez L, Valiente-Soriano FJ, et al. Ocular hypertension impairs optic nerve axonal transport leading to progressive retinal ganglion cell degeneration. Exp Eye Res. 2010;90:168-183.

17. Agudo M, Perez-Marin MC, Lonngren U, et al. Time course profiling of the retinal transcriptome after optic nerve transection and optic nerve crush. Mol Vis. 2008;14:10501063. 
18. Agudo M, Perez-Marin MC, Sobrado-Calvo P, et al. Immediate upregulation of proteins belonging to different branches of the apoptotic cascade in the retina after optic nerve transection and optic nerve crush. Invest Ophthalmol Vis Sci. 2009;50:424-431.

19. Casson RJ, Chidlow G, Wood JP, Vidal-Sanz M, Osborne NN. The effect of retinal ganglion cell injury on light-induced photoreceptor degeneration. Invest Ophthalmol Vis Sci. 2004; 45:685-693.

20. Chidlow G, Casson R, Sobrado-Calvo P, Vidal-Sanz M, Osborne NN. Measurement of retinal injury in the rat after optic nerve transection: an RT-PCR study. Mol Vis. 2005;11:387-396.

21. Nash MS, Osborne NN. Assessment of Thy-1 mRNA levels as an index of retinal ganglion cell damage. Invest Ophthalmol Vis Sci. 1999; 40:1293-1298.

22. Schlamp CL, Johnson EC, Li Y, Morrison JC, Nickells RW. Changes in Thy 1 gene expression associated with damaged retinal ganglion cells. Mol Vis. 2001;7:192-201.

23. Galindo-Romero C, Valiente-Soriano FJ, Jimenez-Lopez M, et al. Effect of brain-derived neurotrophic factor on mouse axotomized retinal ganglion cells and phagocytic microglia. Invest Ophthalmol Vis Sci. 2013;54:974-985.

24. Salvador-Silva M, Vidal-Sanz M, Villegas-Perez MP. Microglial cells in the retina of Carassius auratus: effects of optic nerve crush. J Comp Neurol. 2000;417:431-447.

25. Sobrado-Calvo P, Vidal-Sanz M, Villegas-Perez MP. Rat retinal microglial cells under normal conditions, after optic nerve section, and after optic nerve section and intravitreal injection of trophic factors or macrophage inhibitory factor. $J$ Comp Neurol. 2007;501:866-878.

26. Parrilla-Reverter G, Agudo M, Nadal-Nicolas F, et al. Timecourse of the retinal nerve fibre layer degeneration after complete intra-orbital optic nerve transection or crush: a comparative study. Vision Res. 2009;49:2808-2825.

27. Jehle T, Dimitriu C, Auer S, et al. The neuropeptide NAP provides neuroprotection against retinal ganglion cell damage after retinal ischemia and optic nerve crush. Graefes Arch Clin Exp Ophthalmol. 2008;246:1255-1263.

28. Lindqvist N, Peinado-Ramonn P, Vidal-Sanz M, Hallbook F. GDNF, Ret, GFRalpha1 and 2 in the adult rat retino-tectal system after optic nerve transection. Exp Neurol. 2004;187: 487-499.

29. Mansour-Robaey S, Clarke DB, Wang YC, Bray GM, Aguayo AJ. Effects of ocular injury and administration of brain-derived neurotrophic factor on survival and regrowth of axotomized retinal ganglion cells. Proc Natl Acad Sci U S A. 1994;91:16321636.

30. Peinado-Ramon P, Salvador M, Villegas-Perez MP, Vidal-Sanz M. Effects of axotomy and intraocular administration of NT-4, NT3 , and brain-derived neurotrophic factor on the survival of adult rat retinal ganglion cells. A quantitative in vivo study. Invest Ophthalmol Vis Sci. 1996;37:489-500.

31. Vidal-Sanz M, Lafuente M, Sobrado-Calvo P, et al. Death and neuroprotection of retinal ganglion cells after different types of injury. Neurotox Res. 2000;2:215-227.

32. Vidal-Sanz M, De la Villa $P$, Aviles-Trigueros $M$, et al. Neuroprotection of retinal ganglion cell function and their central nervous system targets. Eye. 2007;21:S42-S45.

33. Aguayo AJ, Vidal-Sanz M, Villegas-Perez MP, Bray GM. Growth and connectivity of axotomized retinal neurons in adult rats with optic nerves substituted by PNS grafts linking the eye and the midbrain. Ann N Y Acad Sci. 1987;495:1-9.

34. Vidal-Sanz M, Bray GM, Villegas-Perez MP, Thanos S, Aguayo AJ. Axonal regeneration and synapse formation in the superior colliculus by retinal ganglion cells in the adult rat. $J$ Neurosci. 1987;7:2894-2909.

35. Aviles-Trigueros M, Sauve Y, Lund RD, Vidal-Sanz M. Selective innervation of retinorecipient brainstem nuclei by retinal ganglion cell axons regenerating through peripheral nerve grafts in adult rats. $J$ Neurosci. 2000;20:361-374.
36. Vidal-Sanz M, Bray GM, Aguayo AJ. Regenerated synapses persist in the superior colliculus after the regrowth of retinal ganglion cell axons. J Neurocytol. 1991;20:940-952.

37. Sasaki H, Coffey P, Villegas-Perez MP, et al. Light induced EEG desynchronization and behavioral arousal in rats with restored retinocollicular projection by peripheral nerve graft. Neurosci Lett. 1996;218:45-48.

38. Vidal-Sanz M, Aviles-Trigueros M, Whiteley SJ, Sauve Y, Lund RD. Reinnervation of the pretectum in adult rats by regenerated retinal ganglion cell axons: anatomical and functional studies. Prog Brain Res. 2002;137:443-452.

39. Whiteley SJ, Sauve Y, Aviles-Trigueros M, Vidal-Sanz M, Lund RD. Extent and duration of recovered pupillary light reflex following retinal ganglion cell axon regeneration through peripheral nerve grafts directed to the pretectum in adult rats. Exp Neurol. 1998;154:560-572.

40. Galindo-Romero C, Aviles-Trigueros M, Jimenez-Lopez M, et al. Axotomy-induced retinal ganglion cell death in adult mice: quantitative and topographic time course analyses. Exp Eye Res. 2011;92:377-387.

41. Nadal-Nicolas FM, Jimenez-Lopez M, Sobrado-Calvo P, et al. $\mathrm{Brn} 3 \mathrm{a}$ as a marker of retinal ganglion cells: qualitative and quantitative time course studies in naive and optic nerveinjured retinas. Invest Ophthalmol Vis Sci. 2009;50:38603868.

42. Parrilla-Reverter G, Agudo M, Sobrado-Calvo P, Salinas-Navarro M, Villegas-Perez MP, Vidal-Sanz M. Effects of different neurotrophic factors on the survival of retinal ganglion cells after a complete intraorbital nerve crush injury: a quantitative in vivo study. Exp Eye Res. 2009;89:32-41.

43. Sanchez-Migallon MC, Nadal-Nicolas FM, Jimenez-Lopez M, Sobrado-Calvo P, Vidal-Sanz M, Agudo-Barriuso M. Brain derived neurotrophic factor maintains Brn3a expression in axotomized rat retinal ganglion cells. Exp Eye Res. 2011;92: 260-267.

44. Villegas-Perez MP, Vidal-Sanz M, Bray GM, Aguayo AJ. Influences of peripheral nerve grafts on the survival and regrowth of axotomized retinal ganglion cells in adult rats. $J$ Neurosci. 1988;8:265-280.

45. Villegas-Perez MP, Vidal-Sanz M, Rasminsky M, Bray GM, Aguayo AJ. Rapid and protracted phases of retinal ganglion cell loss follow axotomy in the optic nerve of adult rats. $J$ Neurobiol. 1993;24:23-36.

46. Berkelaar M, Clarke DB, Wang YC, Bray GM, Aguayo AJ. Axotomy results in delayed death and apoptosis of retinal ganglion cells in adult rats. $J$ Neurosci. 1994;14:4368-4374.

47. Agudo-Barriuso M, Lahoz A, Nadal-Nicolas FM, et al. Metabolomic changes in the rat retina after optic nerve crush. Invest Ophthalmol Vis Sci. 2013;54:4249-4259.

48. Vidal-Sanz M, Salinas-Navarro M, Nadal-Nicolas FM, et al. Understanding glaucomatous damage: anatomical and functional data from ocular hypertensive rodent retinas. Prog Retin Eye Res. 2012;31:1-27.

49. Huang JF, Yu HM, Shang L, et al. The correlation between rat retinal nerve fiber layer thickness around optic disc by using optical coherence tomography and histological measurements. Int J Ophthalmol. 2013;6:415-421.

50. Chauhan BC, Stevens KT, Levesque JM, et al. Longitudinal in vivo imaging of retinal ganglion cells and retinal thickness changes following optic nerve injury in mice. PLoS One. 2012; 7:e40352.

51. Choe TE, Abbott CJ, Piper C, Wang L, Fortune B. Comparison of longitudinal in vivo measurements of retinal nerve fiber layer thickness and retinal ganglion cell density after optic nerve transection in rat. PLOS One. 2014;9:e113011.

52. Abbott CJ, Choe TE, Lusardi TA, Burgoyne CF, Wang L, Fortune B. Evaluation of retinal nerve fiber layer thickness and axonal transport 1 and 2 weeks after 8 hours of acute intraocular pressure elevation in rats. Invest Ophthalmol Vis Sci. 2014;55: 674-687. 
53. Fortune B, Choe TE, Reynaud J, et al. Deformation of the rodent optic nerve head and peripapillary structures during acute intraocular pressure elevation. Invest Ophthalmol Vis Sci. 2011;52:6651-6661.

54. Sarunic MV, Yazdanpanah A, Gibson E, et al. Longitudinal study of retinal degeneration in a rat using spectral domain optical coherence tomography. Opt Express. 2010;18:23435-23441.

55. Nagata A, Higashide T, Ohkubo S, Takeda H, Sugiyama K. In vivo quantitative evaluation of the rat retinal nerve fiber layer with optical coherence tomography. Invest Ophthalmol Vis Sci. 2009;50:2809-2815.

56. Liu Y, McDowell CM, Zhang Z, Tebow HE, Wordinger RJ, Clark AF. Monitoring retinal morphologic and functional changes in mice following optic nerve crush. Invest Ophthalmol Vis Sci. 2014;55:3766-3774.

57. Munguba GC, Galeb S, Liu Y, et al. Nerve fiber layer thinning lags retinal ganglion cell density following crush axonopathy. Invest Ophthalmol Vis Sci. 2014;55:6505-6513.

58. Hein K, Gadjanski I, Kretzschmar B, et al. An optical coherence tomography study on degeneration of retinal nerve fiber layer in rats with autoimmune optic neuritis. Invest Ophthalmol Vis Sci. 2012;53:157-163.

59. Guo L, Normando EM, Nizari S, Lara D, Cordeiro MF. Tracking longitudinal retinal changes in experimental ocular hypertension using the cSLO and spectral domain-OCT. Invest Ophthalmol Vis Sci. 2010;51:6504-6513.

60. Vidal-Sanz M, Villegas-Perez MP, Bray GM, Aguayo AJ. Persistent retrograde labeling of adult rat retinal ganglion cells with the carbocyanine dye diI. Exp Neurol. 1988;102:92-101.

61. Ortin-Martinez A, Valiente-Soriano FJ, Garcia-Ayuso D, et al. A novel in vivo model of focal light emitting diode-induced conephotoreceptor phototoxicity: neuroprotection afforded by brimonidine, BDNF, PEDF or bFGF. PLoS One. 2014;9: e113798.

62. Salinas-Navarro M, Mayor-Torroglosa S, Jimenez-Lopez M, et al. A computerized analysis of the entire retinal ganglion cell population and its spatial distribution in adult rats. Vision Res. 2009; 49:115-126.

63. Nadal-Nicolas FM, Jimenez-Lopez M, Salinas-Navarro M, et al. Whole number, distribution and co-expression of brn3 transcription factors in retinal ganglion cells of adult albino and pigmented rats. PLoS One. 2012;7:e49830.

64. Garcia-Ayuso D, Salinas-Navarro M, Agudo M, et al. Retinal ganglion cell numbers and delayed retinal ganglion cell death in the P23H rat retina. Exp Eye Res. 2010;91:800-810.

65. Garcia-Ayuso D, Salinas-Navarro M, Agudo-Barriuso M, AlarconMartinez L, Vidal-Sanz M, Villegas-Perez MP. Retinal ganglion cell axonal compression by retinal vessels in light-induced retinal degeneration. Mol Vis. 2011;17:1716-1733.

66. Garcia-Ayuso D, Salinas-Navarro M, Nadal-Nicolas FM, et al. Sectorial loss of retinal ganglion cells in inherited photoreceptor degeneration is due to RGC death. Br J Ophthalmol. 2014;98:396-401.

67. Marco-Gomariz MA, Hurtado-Montalban N, Vidal-Sanz M, Lund RD, Villegas-Perez MP. Phototoxic-induced photoreceptor degeneration causes retinal ganglion cell degeneration in pigmented rats. J Comp Neurol. 2006;498:163-179.

68. Villegas-Perez MP, Vidal-Sanz M, Lund RD. Mechanism of retinal ganglion cell loss in inherited retinal dystrophy. Neuroreport. 1996;7:1995-1999.

69. Dieterich DC, Trivedi N, Engelmann R, Gundelfinger ED, Gordon-Weeks PR, Kreutz MR. Partial regeneration and longterm survival of rat retinal ganglion cells after optic nerve crush is accompanied by altered expression, phosphorylation and distribution of cytoskeletal proteins. Eur J Neurosci. 2002; 15:1433-1443.

70. Drager UC, Hofbauer A. Antibodies to heavy neurofilament subunit detect a subpopulation of damaged ganglion cells in retina. Nature. 1984;309:624-626.
71. Villegas-Perez MP, Lawrence JM, Vidal-Sanz M, Lavail MM, Lund RD. Ganglion cell loss in RCS rat retina: a result of compression of axons by contracting intraretinal vessels linked to the pigment epithelium. J Comp Neurol. 1998;392: 58-77.

72. Wang S, Villegas-Perez MP, Vidal-Sanz M, Lund RD. Progressive optic axon dystrophy and vacuslar changes in rd mice. Invest Ophthalmol Vis Sci. 2000;41:537-545.

73. Wang S, Villegas-Perez MP, Holmes T, et al. Evolving neurovascular relationships in the RCS rat with age. Curr Eye Res. 2003;27:183-196.

74. Nadal-Nicolas FM, Salinas-Navarro M, Vidal-Sanz M, AgudoBarriuso M. Two methods to trace retinal ganglion cells with fluorogold: from the intact optic nerve or by stereotactic injection into the optic tract. Exp Eye Res. 2015;131:12-19.

75. Ortin-Martinez A, Jimenez-Lopez M, Nadal-Nicolas FM, et al. Automated quantification and topographical distribution of the whole population of S- and L-cones in adult albino and pigmented rats. Invest Ophthalmol Vis Sci. 2010;51:31713183.

76. Ortin-Martinez A, Salinas-Navarro M, Nadal-Nicolas FM, et al. Laser-induced ocular hypertension in adult rats does not affect non-RGC neurons in the ganglion cell layer but results in protracted severe loss of cone-photoreceptors. Exp Eye Res. 2015; 132:17-33.

77. Sanchez-Migallon Carreras MC, Valiente-Soriano FJ, NadalNicolas FM, et al. Retinal ganglion cell loss and caspase 3 activation after optic nerve crush or transection in mice. Ophthalmic Res. 2014;52:179.

78. de Hoz R, Gallego BI, Ramirez AI, et al. Rod-like microglia are restricted to eyes with laser-induced ocular hypertension but absent from the microglial changes in the contralateral untreated eye. PLoS One. 2013;8:e83733.

79. Rojas B, Gallego BI, Ramirez AI, et al. Microglia in mouse retina contralateral to experimental glaucoma exhibit multiple signs of activation in all retinal layers. J Neuroinflammation. 2014; 11:133.

80. Ramirez AI, Salazar JJ, de HR, et al. Quantification of the effect of different levels of IOP in the astroglia of the rat retina ipsilateral and contralateral to experimental glaucoma. Invest Ophthalmol Vis Sci. 2010;51:5690-5696.

81. Abbott CJ, Choe TE, Burgoyne CF, Cull G, Wang L, Fortune B. Comparison of retinal nerve fiber layer thickness in vivo and axonal transport after chronic intraocular pressure elevation in young versus older rats. PLoS One. 2014;9:e114546.

82. Gallego BI, Salazar JJ, de Hoz R, et al. IOP induces upregulation of GFAP and MHC-II and microglia reactivity in mice retina contralateral to experimental glaucoma. J Neuroinflammation. 2012;9:92.

83. Pease ME, McKinnon SJ, Quigley HA, Kerrigan-Baumrind LA, Zack DJ. Obstructed axonal transport of BDNF and its receptor TrkB in experimental glaucoma. Invest Ophthalmol Vis Sci. 2000;41:764-774.

84. Berger A, Cavallero S, Dominguez E, et al. Spectral-domain optical coherence tomography of the rodent eye: highlighting layers of the outer retina using signal averaging and comparison with histology. PLoS One. 2014;9:e96494.

85. Cuenca N, Fernandez-Sanchez L, Sauve Y, et al. Correlation between SD-OCT, immunocytochemistry and functional findings in an animal model of retinal degeneration. Front Neuroanat. 2014;8:151.

86. Garcia-Martin E, Pinilla I, Sancho E, et al. Optical coherence tomography in retinitis pigmentosa: reproducibility and capacity to detect macular and retinal nerve fiber layer thickness alterations. Retina. 2012;32:1581-1591.

87. Huber G, Beck SC, Grimm C, et al. Spectral domain optical coherence tomography in mouse models of retinal degeneration. Invest Ophthalmol Vis Sci. 2009;50:5888-5895. 